\title{
Intelligent logistics hardware system based on Internet of Things, VR and AR
}

\author{
Liu Kai ${ }^{1, a^{*}}$ Lin XiangMing ${ }^{2, b^{*}}$ Li Yixuan $^{3, c}$ \\ ${ }^{1}$ School of Mathematics and Computer, Xinyu University \\ ${ }^{2}$ School of Economics and Management;Jangxi aviation Vocational \& Technical College \\ ${ }^{3}$ School of Architecture and art, Jiangxi industry Vocational \& Technical College
}

\begin{abstract}
Intelligent logistics refers to the realization of system perception, comprehensive analysis, and timely processing in all aspects of logistics transportation, warehousing, packaging, loading and unloading, circulation processing, distribution, and information services based on information technologies such as the Internet of Things, VR, and artificial intelligence, And the function of self-adjustment. The realization of intelligent logistics can greatly reduce the transportation costs of various related industries, improve transportation efficiency, and enhance corporate profitability. In this paper, the application of intelligent logistics system in Jiangxi railway freight has greatly improved the efficiency of transportation, warehousing, packaging, handling, circulation processing, distribution, and information services.
\end{abstract}

\section{Introduction}

Intelligent logistics refers to the realization of system perception, comprehensive analysis, and timely processing in all aspects of logistics transportation, warehousing, packaging, loading and unloading, circulation processing, distribution, and information services based on information technologies such as the Internet of Things, VR, and artificial intelligence. And the function of self-adjustment. The realization of intelligent logistics can greatly reduce the transportation costs of various related industries, improve transportation efficiency, and enhance corporate profitability. In this paper, the application of intelligent logistics system in Jiangxi railway freight has greatly improved the efficiency of transportation, warehousing, packaging, handling, circulation processing, distribution, and information services.

\section{Related work}

The important role of IoT and cloud computing in collaborative scheduling in logistics system[1]. Intelligent logistics cost control based on 5G network and Internet of Things hardware system. The information system can provide the model and foundation for freight cost management, and the intelligent distributi on details show the best results received by the system[2]. Urban intelligent logistics platform based on FPGA and machine learning[3]. The impact of collaboration is huge, with the potential to eliminate high costs through a network of supply chains. FPGA(Field Programmable Gate Array) uses it to achieve our market goals, provide the best possible service, and create an organizational structure called process information. The Internet of Things (IoT) plays an important role in reducing decision delays and information sharing[4]. Collaborative working methods became critical to the success of the construction industry. BI supports this collaborative way of working and exchanging digital data. Now, ugmented reality (AR) is becoming more common in many genres, and the AEC community is embracing this trend[5] . Logistics elements execution can be improved by augmented reality (AR) technologies. Object pickup time can be decreased in human operated warehouses[6]. The application of augmented reality technology in warehouse logistics is still in its infancy. To be sure, the room for improvement is as great as their potential[7]. Augmented reality is a visualization solution for logistics and warehousing management and employee training. Users can be immersed in the real environment and managed objects without causing physical and mental discomfort[8]. Microsoft released head-mounted mixed reality (MR) applications in the production and logistics industry[9]. In recent years, the rapid development of the Internet of Things, VR and VR technologies has opened up new paths for modern logistics companies. Companies actively embracing new technologies are the key to enhancing their core competitiveness and an important source of profit.

\section{Intelligent logistics}

Intelligent logistics is a complex system. Including transportation, containers, warehousing, ports, platforms, shelves, to all possible personnel and information exchanges in the logistics chain, and integrated management that integrates related activities in the logistics chain. Through intelligent hardware, Internet of

\footnotetext{
a*Corresponding author. Email:a liukai_work@163.com *bblxm594@vip.qq.com

c476814305@qq.com
} 
Things, big data and other intelligent technologies.

\subsection{Application of VR technology in logistics system}

VR technology involves computer graphics, sensor technology, human-computer interaction technology, artificial intelligence and other fields. It is a technology that uses a computer system to construct a realistic threedimensional space through certain instruments and equipment. Users can achieve the integration of visual, tactile, auditory and other aspects with the presentation screen by wearing VR helmets, headsets, and holding data controllers, so that they can produce an immersive feeling. The user in the experience is not only A third party in the bystander position can also operate the scene in the threedimensional space through data handles and other equipment. The things in the scene will also respond accordingly to the user's actions or operations, which is a kind of feedback, New technology with strong interactivity. The introduction of VR technology in the training of new employees and new skills can reduce costs, improve training efficiency, and greatly shorten the time on duty. VR realistic logistics environment, such as warehouse layout, logistics equipment, port logistics, roaming logistics park, etc., employees are immersed in In the real logistics work scene generated by virtual simulation technology, experience, feel and interact actively. VR technology is applied to the logistics training industry. The application of VR technology is shown in Figure 1.

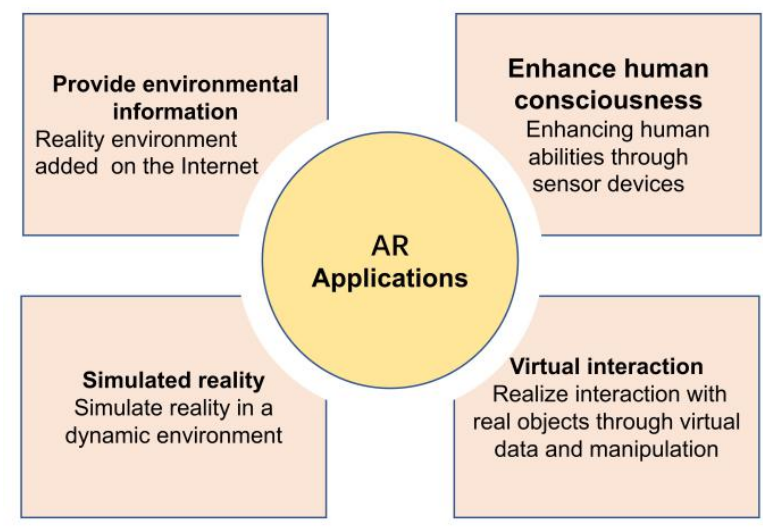

Figure 1 Application of VR technology

\subsection{Application of Internet of Things in Logistics System}

With the advent of the era of the Internet of Everything, the logistics industry is gradually developing in the direction of intelligence, and the Internet of Things plays an important driving role in the intelligent development of the logistics industry. The core of logistics is the flow of goods or commodities, and the Internet of Things focuses on things. After identifying and collecting a large amount of object information through a variety of sensing technologies, it connects various object information data to form a data network. Then use cloud computing, big data, edge computing and other technologies for intelligent processing, Realize the intelligent connection of things, so it has high applicability in the logistics field, and can further strengthen the monitoring of items in warehousing, transportation, distribution and other links, accelerate the speed of obtaining item status information, improve the level of item safety management, and improve the efficiency of logistics operations. The business application of the Internet of Things in logistics companies is shown in Figure 2.

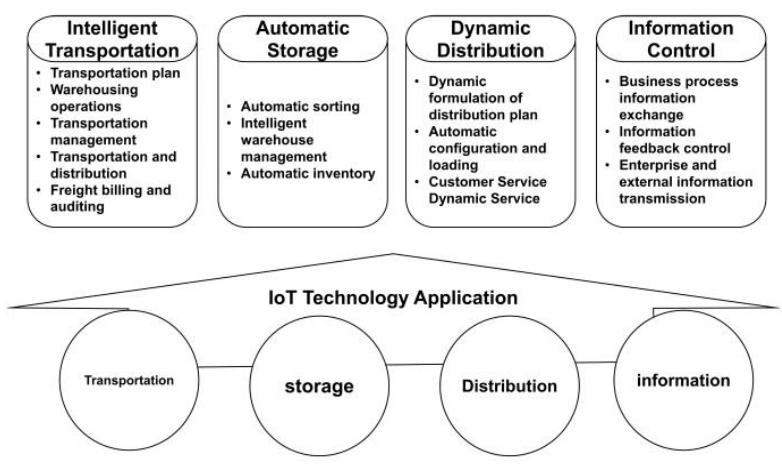

Figure 2 Business Application of Internet of Things in Logistics Enterprises

\subsection{Intelligent logistics system}

The Intelligent logistics system includes 5 levels horizontally, and 5 levels cover Full Chain, Full Channel, Full Scene, Full Technology, and Full Goal. According to the direction of goods circulation, it is divided into TOA Stage (commodity production), TOB Stage (commodity circulation), and TOC Stage (commodity consumption). The personnel covered by the system include: Raw material supplier, Manufacturer, Regional Agent, Retailer, E-commerce Platform, User, Intelligent logistics system uses technologies including Big data, Internet OF Things, AI, Blockchain Traceability, Cloud Computing. The architecture of the intelligent logistics system is shown in the figure 3 .

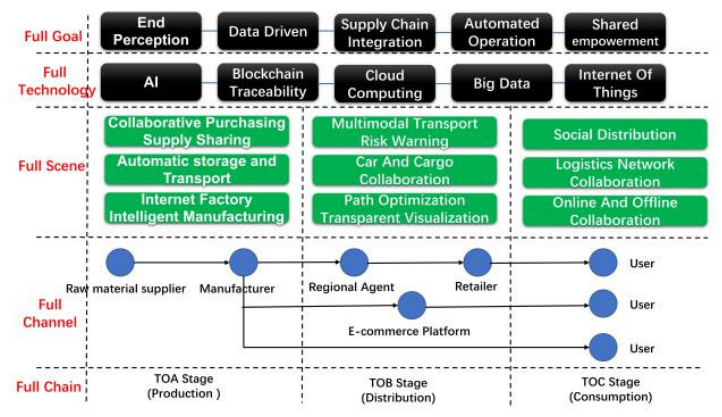

Figure 3 Intelligent logistics integrated architecture

\section{Application of Intelligent logistics system}

The realization of smart logistics can greatly reduce the transportation costs of various related industries, improve transportation efficiency, and enhance corporate profits. The Internet of Things is applied to three aspects of the logistics industry, namely, cargo warehousing, 
transportation monitoring, and smart express terminals.

\subsection{Cargo storage}

In traditional warehousing, manual cargo scanning and data entry are often required, which results in low work efficiency. At the same time, storage locations are sometimes unclear, stacked in confusion, and lack of process tracking. Applying the Internet of Things technology to traditional warehousing to form an intelligent warehouse management system can improve the efficiency of goods in and out, expand the storage capacity, reduce labor intensity and labor costs, and can display and monitor the in and out of goods in real time to improve delivery Accuracy, complete the tasks of receiving goods into storage, inventory allocation, picking out of storage, as well as data query, backup, statistics, report production and report management of the entire system.

\subsection{Transport monitoring}

Real-time monitoring of transported trucks and goods through the logistics vehicle management system can complete real-time, positioning and tracking of vehicles and goods, monitor the status and temperature and humidity of the goods, and monitor the speed of transport vehicles, tire temperature, tire pressure, fuel consumption and fuel consumption, Vehicle speed and other driving behaviors such as the number of brakes and driving behavior, in the process of cargo transportation, the information such as cargo, driver and vehicle driving conditions are efficiently combined to improve transportation efficiency, reduce transportation costs, reduce cargo losses, and clearly understand transportation Everything in the process.

\subsection{Smart express cabinet}

The smart express cabinet is based on the Internet of Things technology, capable of identifying, storing, monitoring, and managing objects. Together with the PC server, it forms an intelligent express delivery system. The PC server can process the information data collected by the smart express terminal and update it in the data background in real time, which is convenient for users to query express delivery, deploy express delivery, and express terminal maintenance.

\subsection{New employee training}

The introduction of VR technology in the training of new employees and new skills can reduce costs, improve training efficiency, and greatly shorten the time on duty. VR realistic logistics environment, such as warehouse layout, logistics equipment, port logistics, roaming logistics park, etc., employees are immersed in In the real logistics work scene generated by virtual simulation technology, experience, feel and interact actively.

\section{CONCLUSION}

We chose the Lehua Logistics Base of Nanchang Section of Beijing-Kowloon Railway to apply the intelligent logistics system and select 6 common goods. The annual revenue of the system was 3.63 million yuan before the system was used, and 4.28 million yuan after the use. The annual revenue growth rate is $15.19 \%$, as shown in Figure 4. The introduction of the smart logistics system accelerates the flow of corporate goods, reduces labor costs, and significantly improves corporate profits.

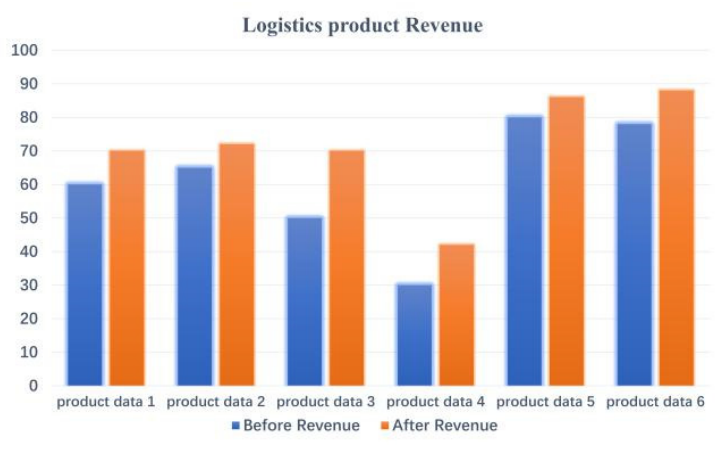

Figure 4 Logistics product Revenue

\section{AUTHORS' CONTRIBUTIONS}

Liu Kai is responsible for the design of Intelligent logistics hardware system, and writing papers, and Lin Xiangmin is responsible for enterprise implementation and research.

\section{ACKNOWLEDGMENTS}

Thank the work unit for giving us a superior platform to write papers and obtain experimental data, thank the partners for their strong support, and thank the family for their selfless dedication. Without your support, we would not be successful.

\section{REFERENCES}

1. Zhou, L., L. Zhang, and B.K.P. Horn, Collaborative optimization for logistics and processing services in cloud manufacturing. Robotics and ComputerIntegrated Manufacturing, 2021. 68 DOI:https://doi.org/10.1016/j.rcim.2020.102094.

2. Yan, L. and Z. Peng, The Research of Cost Control about the Third Party Logistics Enterprise Based on Activity-Based Costing Model. 2015 8th International Conference on Intelligent Computation Technology and Automation (ICICTA), 2015: p. 1018-1021

DOI:https://doi.org/10.1109/icicta.2015.282.

3. Yanxia, Z., Z. Maoran, and J. Nan, Urban smart logistics platform based on FPGA and machine learning. Microprocessors and Microsystems, 2020 DOI:https://doi.org/10.1016/j.micpro.2020.103474.

4. Zhou, Z., et al., Logistics supply chain information collaboration based on FPGA and internet of things 
system. Microprocessors and Microsystems, 2021. 80 DOI:https://doi.org/10.1016/j.micpro.2020.103589.

5. Garbett, J., T. Hartley, and D. Heesom, A multi-user collaborative BIM-AR system to support design and construction. Automation in Construction, 2021. 122 DOI:https://doi.org/10.1016/j.autcon.2020.103487.

6. Cirulis, A. and E. Ginters, Augmented Reality in Logistics. Procedia Computer Science, 2013. 26: p. 14-20 DOI:https://doi.org/10.1016/j.procs.2013.12.003.

7. G. Plakas, et al., Augmented Reality in Manufacturing and Logistics. Procedia Manufacturing, 2020. 51: p. 1629-1635.

8. Ginters, E. and J. Martin-Gutierrez, Low Cost Augmented Reality and RFID Application for Logistics Items Visualization. Procedia Computer Science, 2013. 26: p. $3-13$ DOI:https://doi.org/10.1016/j.procs.2013.12.002.

9. Sebastian Lang, et al., Mixed reality in production and logistics: Discussing the application potentials of Microsoft HoloLens Procedia Computer Science, 2019: p. 118-129. 